\title{
Eosinophilic gastroenteritis as a cause of non-Helicobacter pylori, non-gastrotoxic drug ulcers in children
}

\author{
Jung Yeon Joo', Jin Min Cho', In Hyuk Yoo ${ }^{1}$ and Hye Ran Yang ${ }^{1,2^{*}}$ (D)
}

\begin{abstract}
Background: While Helicobacter pylori (H. pylori) ulcers has declined recently, H. pylori-negative and/or gastrotoxic drug-negative peptic ulcers (HNGN-PU) has increased. This study aimed to analyze the etiology of peptic ulcers in children and the differences in clinical, laboratory, endoscopic, and histopathologic findings of peptic ulcers according to etiology, including eosinophilic gastroenteritis (EOGE).
\end{abstract}

Methods: In total, 255 children (157 boys and 98 girls) with peptic ulcers were recruited. The subjects were categorized into 5 groups according to the etiology of the ulcer: 1) H. pylori infection $(n=51)$; 2$)$ gastrotoxic drugs $(n=18) ; 3)$ idiopathic $(n=144) ; 4)$ systemic disease $(n=23) ; 5)$ EoGE $(n=19)$. Clinical data were reviewed and analyzed retrospectively.

Results: Age at diagnosis, ulcer recurrence, atopic dermatitis history, white blood cell count, blood eosinophil count, platelet count, serum albumin level, iron level, erythrocyte sedimentation rate, and C-reactive protein level differed significantly among the 5 groups (all $p<0.05$ ). Regarding endoscopic findings, multiple ulcers and gastric mucosal nodularity differed among the 5 groups (all $p<0.05$ ). When comparing the EoGE ulcer group with the others, EoGE group revealed older ages $(p=0.022)$, higher rates of ulcer recurrence $(p=0.018)$, atopic dermatitis history $(p=0.001)$, and both blood and tissue eosinophilia (both $p=0.001$ ).

Conclusions: EoGE ulcers constituted $10.2 \%$ of HNGN-PU in pediatric patients. In children with HNGN-PU, peripheral eosinophilia, ulcer recurrence, and atopic dermatitis history might imply EoGE, necessitating thorough investigation of tissue eosinophils during endoscopic biopsy.

Trial registration: A total of 255 children was retrospectively registered between between July 2003 and April 2017.

Keywords: Peptic ulcer, Eosinophilic gastroenteritis, Eosinophilia, Helicobacter pylori, Non-steroidal anti-inflammatory agents, Child

\footnotetext{
* Correspondence: hryang@snubh.org; hrlamb2@snu.ac.kr

'Department of Pediatrics, Seoul National University Bundang Hospital, Seoul

National University, 82, Gumi-ro 173 Beon-gil, Bundang-gu, Seongnam-si,

Gyeonggi-do 13620, South Korea

${ }^{2}$ Seoul National University College of Medicine, Seoul, South Korea
}

(c) The Author(s). 2020 Open Access This article is licensed under a Creative Commons Attribution 4.0 International License, which permits use, sharing, adaptation, distribution and reproduction in any medium or format, as long as you give appropriate credit to the original author(s) and the source, provide a link to the Creative Commons licence, and indicate if changes were made. The images or other third party material in this article are included in the article's Creative Commons licence, unless indicated otherwise in a credit line to the material. If material is not included in the article's Creative Commons licence and your intended use is not permitted by statutory regulation or exceeds the permitted use, you will need to obtain permission directly from the copyright holder. To view a copy of this licence, visit http://creativecommons.org/licenses/by/4.0/ The Creative Commons Public Domain Dedication waiver (http://creativecommons.org/publicdomain/zero/1.0/) applies to the data made available in this article, unless otherwise stated in a credit line to the data. 


\section{Background}

Peptic ulcer disease is mainly associated with Helicobacter pylori (H. pylori) infection [1-4], and the use of gastrotoxic drugs such as non-steroidal anti-inflammatory drugs (NSAIDs) [5]. However, in the last decade, the main etiology of peptic ulcer disease has changed significantly in both children and adults from both eastern and western countries [6-8]. The prevalence of both $H$. pylori ulcer and gastrotoxic drug peptic ulcer has declined due to improved eradication therapy for $H$. pylori infection and reduced use of NSAIDs, respectively [9-11], while there have been several reports on the recurrence of peptic ulcers after the eradication of $H$. pylori in nonusers of NSAIDs $[6,12,13]$. Thus, $H$. pylori-negative and/or gastrotoxic drug-negative peptic ulcer (HNGNPU) has emerged as a "new" disease entity [14, 15].

Most cases of $H$. pylori-negative peptic ulcers are caused by NSAIDs in adults [5], but not in children. Although the prevalence of HNGN-PU is reported to be higher in children than in adults $[6,16]$, the exact etiology of HNGN-PU in children is unclear and has not been investigated yet.

Eosinophilic gastroenteritis (EoGE) is an inflammatory disorder characterized by eosinophilic infiltration of the stomach and/or duodenum. In some cases, inflammation of the esophagus, distal intestine, and colon may also be present. EoGE occurs without any other known cause of tissue eosinophilia. Vomiting, abdominal pain, and growth retardation are the most common symptoms [17], and approximately $40 \%$ of patients with EoGE have a history of allergic disease including asthma, eczema, or rhinitis [17-19]. Previous studies in adult patients have reported EoGE to be a cause of intractable peptic ulcers in some patients. However, there have been no studies investigating EoGE as the etiology of peptic ulcers in children yet, even though EoGE can be a potential etiology of HNGN-PU in children.

The present study was aimed at analyzing the etiology of HNGN-PU in children and investigating the differences in clinical, laboratory, endoscopic, and histopathologic findings of peptic ulcers according to etiology including $H$. pylori infection, gastrotoxic drugs, systemic diseases, eosinophilic gastroenteritis (EoGE), and idiopathic peptic ulcers.

\section{Methods}

\section{Study population and data collection}

Of 1694 children and adolescents aged 18 or less who visited the Department of Pediatric Gastroenterology in Seoul National University Bundang Hospital with upper gastrointestinal symptoms and underwent esophagogastroduodenoscopy with biopsy between July 2003 and April 2017, 255 children diagnosed with peptic ulcers on endoscopy were recruited. The study subjects were categorized into 5 groups according to the etiology of the ulcer: 1) $H$. pylori infection $(n=51)$; 2) gastrotoxic drugs $(n=18)$; 3$)$ idiopathic peptic ulcers $(n=144) ; 4)$ systemic diseases such as Henoch-Schönlein purpura (HSP) and Crohn's disease $(n=23)$; and 5) EoGE ( $n=$ 19). Anastomosis site ulcer after gastrojejunostomy was excluded from the study. Patients referred from other hospitals after upper endoscopy and those transferred after ulcer treatment were also excluded.

Medical records of participants including demographic data, clinical features, allergy history, drug history, endoscopic findings, histopathologic findings, and laboratory tests were reviewed and analyzed retrospectively. Medication history was defined as drug intake during the 4week period before diagnosis. Gastrotoxic drugs included NSAIDs or steroid usages, alkali ingestion, and disc battery ingestion.

This retrospective study was approved by the Institutional Review Board (IRB) of Seoul National University Bundang Hospital (IRB No. B-1707/409-105).

\section{Laboratory tests and radiologic investigations}

All participants underwent laboratory tests including complete blood cell counts such as white blood cell count (WBC), absolute neutrophil count (ANC), eosinophil count, hemoglobin, hematocrit, platelet count, erythrocyte sedimentation rate (ESR), highly sensitive Creactive protein (hSCRP), protein, albumin, liver function tests, serum amylase, lipase, iron panel, ferritin, urinalysis and urine cultures, stool examination for parasite, fecal occult blood, and fecal calprotectin levels, as well as abdominal X-ray and abdominal ultrasonography.

\section{Endoscopic evaluation}

Esophagogastroduodenoscopy with mucosal biopsies was performed in all 255 study participants using a GIFXP260 or GIF-Q260 scope (Olympus, Tokyo, Japan). Diagnosis of peptic ulcers was made based on endoscopic findings, which included the location, size, and number of ulcers and ulcer recurrence.

Colonoscopy with mucosal biopsies was performed additionally in 23 patients, to rule out gastric or duodenal ulcers due to systemic diseases.

\section{Histopathologic evaluation}

Endoscopic mucosal biopsies were obtained from the esophagus, gastric antrum and body, and duodenum, during the upper gastrointestinal endoscopy, in all participants. Biopsy tissues were immediately fixed in formalin-filled bottle and processed to paraffin wax. Sections were cut at $3 \mu \mathrm{m}$ and stained with hematoxylineosin and Wright-Giemsa stain for $H$ pylori.

Modified Sydney classification was used to test for $H$ pylori colonization, polymorphonuclear neutrophil 
activity, mononuclear cell infiltration, glandular atrophy, and intestinal metaplasia of the gastric tissue from the antrum and body. For the histopathologic diagnosis of $H$ pylori infection, the specimens were subjected to rapid urease test in addition to histopathologic examination. $H$ pylori infection was diagnosed if two endoscopic tests were positive for $\mathrm{H}$ pylori. For the rapid urease test kit (CLOtest, Ballard Inc., Draper, UT), the inoculated specimen was interpreted as positive if its color changed from yellow to pink within $24 \mathrm{~h}$.

For the diagnosis of EoGE, tissue eosinophils were counted in 5 randomly selected high-power fields. Quantification of eosinophils was performed using an Axioskop40 microscope (Mirax-Carl Zeiss, Oberkochen, Germany) at 400x magnification. Histopathologic diagnosis of EoGE was made when the total number of infiltrating eosinophils per high power field was more than 15 in the esophagus and more than 20 in the stomach and duodenum without any other organic causes of tissue eosinophilia.

\section{Statistical analysis}

Data for continuous parametric variables are presented as mean and standard deviations and that for categorical variables are presented as a percentage of the total number.

All statistical analyses were performed using PASW Statistics (SPSS version 22.0, SPSS Inc., Chicago, IL, USA). Continuous data were analyzed using the MannWhitney $U$ test of two independent samples to compare two quantitative nonparametric variables and the Kruskal-Wallis test of independent samples to compare three or more quantitative nonparametric variables. Chisquare tests were used to compare categorical variables.

For statistical analysis of the differences in nonparametric continuous variables between the two groups, the Mann-Whitney test was additionally applied. The Bonferroni correction method was used to test and verity the variables marked as having differences. The significance level was divided by the number of comparison $[\alpha=0.005(0.05 / 10)]$ and then the Mann-Whitney test was performed.

For all statistical analyses, a two-sided $p$ value $<0.05$ was considered statistically significant.

\section{Results}

\section{Patient characteristics of children with peptic ulcers}

Totally 255 (15\%) children out of 1694 patients who had undergone upper endoscopy for investigation of upper gastrointestinal symptoms, during the study period, were identified to have gastric or duodenal ulcers, on endoscopy, among whom one patient with anastomosis site ulcer was excluded from the study. These 255 children included 157 boys and 98 girls, with a mean age of $10.0 \pm 5.1$ years (range; 1 day $\sim 18.0$ years).
Of the 255 pediatric patients with peptic ulcers, 159 (62.4\%) and 69 (27.1\%) patients had only duodenal ulcers and gastric ulcers, respectively. Both gastric and duodenal ulcers were observed in 27 (10.6\%) patients and multiple ulcers were observed in 73 (28.6\%) patients, on endoscopy.

Regarding the etiology of peptic ulcers, H. pylori infection was diagnosed in 51 (20.0\%) of the 255 patients; history of preceding gastrotoxic drugs intake in 18 (7.1\%); systemic diseases such as Crohn's disease and HSP in 23 (9.0\%); EoGE-related peptic ulcers in 19 (7.5\%); and idiopathic peptic ulcers in 144 (56.4\%) patients (Table 1 ). EoGE ulcers accounted for $10.2 \%$ of 186 HNGN-PU in pediatric patients.

\section{Changes in the diagnosis of causes of peptic ulcers in children during the study period}

Figure 1 reveals the distribution of the etiology of peptic ulcers in children during the study period from 2003 to 2017. Since the introduction of a new protocol for histopathologic evaluation of endoscopic biopsy to count tissue eosinophils in all specimens in 2011, the distribution of causes of HNGN-PU changed and EoGE newly emerged as a cause of peptic ulcers in children (Fig. 1).

\section{Comparison of clinical and laboratory factors among the 5 groups according to the etiology of peptic ulcers in children}

Regarding clinical factors related to peptic ulcers in children, age at diagnosis $(p<0.001)$, history of atopic dermatitis $(p=0.002)$, and ulcer recurrence $(p=0.016)$ were significantly different among the 5 peptic ulcer groups (Table 1). When applying the post-test analysis between the two groups, statistically significant differences were found between the $H$. pylori infection group and the idiopathic peptic ulcer group at the significance level of 0.005 (Supplement 1). Idiopathic peptic ulcer group showed statistically significant differences in atopic dermatitis history, duodenal ulcer, and peripheral eosinophilia compared to $H$. pylori infection group.

Regarding laboratory factors, WBC counts $(p=0.008)$, eosinophil counts in blood $(p=0.013)$, platelet counts $(p<0.001)$, serum levels of albumin $(p=0.027)$, iron $(p<$ $0.001)$, ESR $(p<0.001)$, and hsCRP $(p=0.016)$ differed significantly among the 5 ulcer groups (Table 2 ).

\section{Comparison of endoscopic and histopathologic findings among the $\mathbf{5}$ groups according to the etiology of peptic ulcers in children}

Regarding endoscopic findings, gastric ulcers $(p=0.005)$, duodenal ulcers $(p<0.001)$, multiple ulcers $(p=0.023)$, and gastric mucosal nodularity $(p<0.001)$ differed significantly among the 5 peptic ulcer groups (Table 1 ). Gastric ulcers were most frequently observed on upper 
Table 1 Comparison of clinical features, endoscopic and histopathologic findings of children with peptic ulcers according to the etiology of ulcer

\begin{tabular}{|c|c|c|c|c|c|c|}
\hline Variable & $\begin{array}{l}\text { H. pylori } \\
\text { infection } \\
(n=51)\end{array}$ & $\begin{array}{l}\text { Gastrotoxic } \\
\text { drug } \\
(n=18)\end{array}$ & $\begin{array}{l}\text { Idiopathic peptic } \\
\text { ulcer } \\
(n=144)\end{array}$ & $\begin{array}{l}\text { Systemic } \\
\text { disease } \\
(n=23)\end{array}$ & $\begin{array}{l}\text { Eosinophilic } \\
\text { gastroenteritis } \\
(N=19)\end{array}$ & $P$ value* \\
\hline \multicolumn{7}{|l|}{ Clinical features } \\
\hline Male gender & $34(66.7)$ & $7(38.9)$ & $86(59.7)$ & $15(65.2)$ & $15(78.9)$ & \\
\hline Age, years & $14.3(2.0-17.9)$ & $6.0(1.5-17.5)$ & 9.1 (1 day-17.6) & $8.6(1.5-4.7)$ & $13.6(5.4-17.4)$ & $<0.001$ \\
\hline \multicolumn{7}{|l|}{ Allergic history } \\
\hline$A D$ & 0 & 0 & $4(2.8)$ & $1(4.3)$ & $5(26.3)$ & 0.002 \\
\hline$A R$ & $1(4.3)$ & $1(7.7)$ & $8(9.4)$ & 0 & $2(14.3)$ & 0.603 \\
\hline Asthma & $1(4.3)$ & $1(7.7)$ & $1(1.2)$ & 0 & 0 & 0.305 \\
\hline Complications & $6(11.8)$ & $1(5.6)$ & $10(6.9)$ & $1(4.3)$ & $3(15.8)$ & 0.742 \\
\hline Bleeding & $4(7.8)$ & $1(5.6)$ & $7(4.9)$ & $1(4.3)$ & $2(10.5)$ & 0.940 \\
\hline Obstruction & $2(3.9)$ & 0 & $1(0.7)$ & 0 & $1(5.3)$ & 0.424 \\
\hline Perforation & 0 & 0 & $2(1.4)$ & 0 & 0 & 0.770 \\
\hline Ulcer recurrence & $5(9.8)$ & 0 & $3(2.1)$ & $3(13)$ & $4(21.1)$ & 0.016 \\
\hline \multicolumn{7}{|l|}{ Endoscopic findings $\mathrm{n},(\%)$} \\
\hline Gastric ulcer only & $10(19.6)$ & $11(61.1)$ & $42(29.2)$ & $4(17.4)$ & $2(10.5)$ & 0.005 \\
\hline Duodenal ulcer only & $34(66.7)$ & $3(16.7)$ & $92(63.9)$ & $15(65.2)$ & $15(78.9)$ & $<0.001$ \\
\hline $\begin{array}{l}\text { Both gastric and duodenal } \\
\text { ulcers }\end{array}$ & $7(13.7)$ & $4(22.2)$ & $10(6.9)$ & $4(17.4)$ & $2(10.5)$ & 0.427 \\
\hline Multiple ulcers & $9(17.6)$ & $9(50)$ & $40(27.8)$ & $11(47.8)$ & $4(21.1)$ & 0.023 \\
\hline Gastric nodularity & $27(52.9)$ & 0 & $8(5.6)$ & $1(4.3)$ & $5(26.3)$ & $<0.001$ \\
\hline Duodenal Nodularity & $2(3.9)$ & 0 & $8(5.6)$ & 0 & 0 & 0.519 \\
\hline \multicolumn{7}{|c|}{ Tissue eosinophils (count/HPF) $n$, (range) } \\
\hline Upper esophagus & $0(0-40)$ & $0(0)$ & $0(0-4)$ & $0(0-3)$ & $0(0-103)$ & $<0.001$ \\
\hline Lower esophagus & $0(0-27)$ & $0(0)$ & $0(0-24)$ & $0(0)$ & $0(0-100)$ & $<0.001$ \\
\hline Stomach antrum & $0(0-18)$ & $0(0-2)$ & $0(0-20)$ & $9(0-12)$ & $5(0-168)$ & $<0.001$ \\
\hline Stomach body & $0(0-18)$ & $0(0-2)$ & $0(0-20)$ & $0(0-8)$ & $1(0-55)$ & $<0.001$ \\
\hline Duodenal bulb & $0(0-53)$ & $0(0-10)$ & $0(0-18)$ & $9(0-6)$ & $35(0-84)$ & $<0.001$ \\
\hline Duodenal 2nd & $0(0-42)$ & $0(0-10)$ & $0(0-19)$ & $0(0-25)$ & $25(0-100)$ & $<0.001$ \\
\hline
\end{tabular}

Data are expressed as number (\%) for categorical variables or median (range) for continuous variables $A D$ atopic dermatitis, $A R$ allergic rhinitis, EoGE eosinophilic gastroenteritis, HPF high power field

*P value less than 0.05 was set to be statistically significant

endoscopy in the gastrotoxic drug group (61.1\%), followed by the idiopathic ulcer group (29.2\%) (Table 1). Duodenal ulcers were most frequently noted in the EoGE group (78.9\%), followed by the H. pylori group (66.7\%) and the systemic disease group (65.2\%) (Table 1). According to the results of the post-test for duodenal ulcer, there was a statistically significant difference between the $H$. pylori infection group and the idiopathic peptic ulcer group at the significance level of 0.005 (Supplement 1). Gastric mucosa nodularity was most frequently noted in the $H$. pylori group (52.9\%), followed by the EoGE group (26.3\%) (Table 1 ).

Regarding histopathologic findings of upper gastrointestinal tracts, tissue eosinophil counts were significantly different in the esophagus, stomach, and duodenum among the 5 ulcer groups (all $p<0.001$ ) (Table 1).

\section{Comparison of EoGE ulcers with non-EoGE ulcers}

When clinical features of EoGE ulcers were compared with those of the other groups, the patients with EoGE ulcers were significantly older in age (median 13.6 yrs. vs. 10.2 years, $p=0.022$ ) and revealed higher rates of ulcer recurrence (21.1\% in EoGE group vs. $4.7 \%$ in nonEoGE group, $p=0.018$ ), and atopic dermatitis history (26.3\% in EoGE group vs. $2.1 \%$ in non-EoGE group, $p=$ 0.001) (Tables 3 and 4).

When comparing the laboratory, endoscopic, and histopathologic findings of the EoGE group and the nonEoGE ulcer groups, only blood eosinophil counts and 


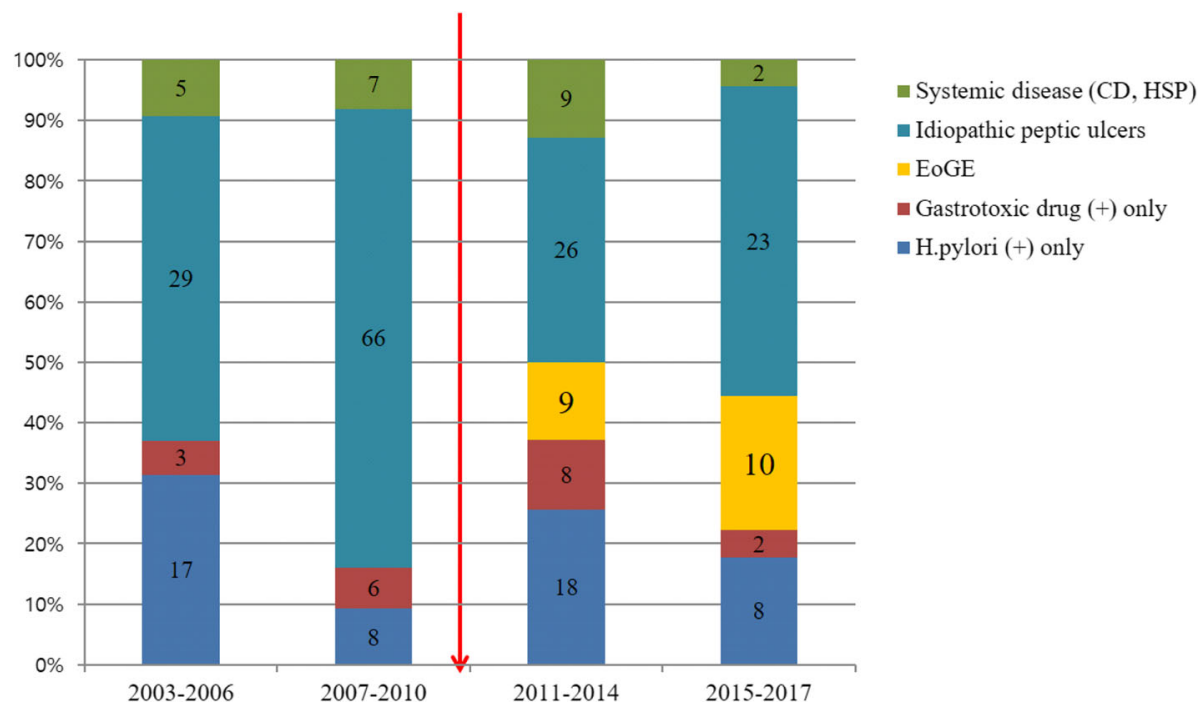

Fig. 1 Distribution of the etiology of peptic ulcers in children by period. There is a change in the etiology of non-H. pyloriand non-gastrotoxic drug ulcers since the new endoscopic biopsy protocol was implemented in 2011 to count tissue eosinophils in all specimens and eosinophilic gastroenteritis newly emerged as a cause of peptic ulcers in children.CD, Crohn's disease; EoGE, eosinophilic gastroenteritis; HSP,

Henoch-Schönlein purpura

tissue eosinophil counts of the esophagus, stomach, and duodenum were significantly higher in the EoGE group $(p=0.001 \quad \& \quad p<0.001$, respectively) (Supplemental Digital Content $1 \&$ Table 3).

\section{Discussion}

This is the first study that investigated the etiology of peptic ulcers in pediatric patients and its change over time, especially emphasizing on HNGN-PU as an emerging etiology of peptic ulcers and EoGE as a significant cause of HNGN-PU in children.

Previously, H. pylori infection and gastrotoxic drugs were considered the main causes of peptic ulcers [1-4]. In developing countries including South Korea, the prevalence of $H$. pylori infection has increased to $50 \%$ of the general population, and in $15 \%$ of the infected patients, $H$. pylori infection led to the development of peptic ulcers. Additionally, $H$. pylori-negative duodenal ulcers were reported in several studies in the early 1990s

Table 2 Comparison of laboratory findings of children with peptic ulcers according to the etiology of ulcer

\begin{tabular}{|c|c|c|c|c|c|c|}
\hline Variable, n (\%) & $\begin{array}{l}\text { H. pylori infection } \\
(N=51)\end{array}$ & $\begin{array}{l}\text { Gastrotoxic drug } \\
(N=18)\end{array}$ & $\begin{array}{l}\text { Idiopathic peptic ulcer } \\
(N=144)\end{array}$ & $\begin{array}{l}\text { Systemic disease } \\
(N=23)\end{array}$ & $\begin{array}{l}\text { Eosinophilic gastroenteritis } \\
(N=19)\end{array}$ & $P$ value $^{*}$ \\
\hline WBC $(\times 103 / \mu l)$ & $6.5(3.2-13.3)$ & $7.7(4.5-26.1)$ & $7.4(3.3-29.7)$ & $8.9(5-18.9)$ & $6.4(4.2-10.3)$ & 0.008 \\
\hline ANC $(\mu \mathrm{l})$ & $3644(1450-10,600)$ & $3161(1663-22,933)$ & $3649(521-18,680)$ & $4706(1268-16,795)$ & 3157 (1819-6874) & 0.064 \\
\hline Eosinophil (\%) & $2(0.6-12.1)$ & $2.25(0.1-5.7)$ & $2.4(0-13.4)$ & $1.4(0.1-6.3)$ & $4.5(1.3-22.5)$ & 0.009 \\
\hline Hematocrit (\%) & $38.8(18.8-49.9)$ & 39.1 (31.2-43.3) & $39.5(22.3-58.3)$ & $27.6(26.0-47.5)$ & $40(22.3-45.9)$ & 0.395 \\
\hline Hemoglobin ( $\mathrm{g} / \mathrm{dL}$ ) & $12.9(8.0-16.4)$ & $12.9(9.9-14.3)$ & $13.3(6.2-20.3)$ & $12.5(8.8-15.6)$ & $13.5(7.5-15.3)$ & 0.303 \\
\hline Platelet $(\times 103 / \mu l)$ & $276(133-579)$ & $348(115-470)$ & $278(10-574)$ & $382(150-560)$ & $296(135-577)$ & 0.000 \\
\hline Protein (g/dL) & $7.1(5.0-8.3)$ & $6.9(6.1-7.7)$ & $7.0(4.2-8.5)$ & $6.8(5.0-9.0)$ & $6.9(6.3-7.7)$ & 0.734 \\
\hline Albumin (g/dL) & $4.5(3.0-5.0)$ & $4.2(3.3-5.0)$ & $4.4(2.4-5.4)$ & $3.8(3.2-4.8)$ & $4.4(3.8-5.5)$ & 0.027 \\
\hline Iron $(\mu \mathrm{g} / \mathrm{dL})$ & $57(10-172)$ & $85(26-107)$ & 78.5 (9-208) & $27.5(12.0-126.0)$ & 64.5 (12.0-199) & 0.001 \\
\hline Ferritin (ng/ml) & 28.8 (1.9-99.0) & $49.2(32.4-81.0)$ & $43.7(6-217)$ & $17.9(4.0-183.8)$ & $44.0(4-164)$ & 0.055 \\
\hline TIBC $(\mu \mathrm{g} / \mathrm{dL})$ & $388(280-580)$ & $329.5(220-459)$ & $358(188-528)$ & 363.5 (248.0-486.0) & $265(251-463)$ & 0.506 \\
\hline ESR $(\mathrm{mm} / \mathrm{hr})$ & $6(2-52)$ & $11.0(2-17)$ & $4(2-79)$ & $25.5(4.0-59.0)$ & $4(2-21)$ & 0.000 \\
\hline hsCRP (mg/dL) & $0.02(0-18.4)$ & $0.3(0-2.6)$ & $0.12(2-24.6)$ & $1.3(0-4.4)$ & $0.02(0-5.3)$ & 0.016 \\
\hline
\end{tabular}

Data are expressed as median (range)

$A N C$ absolute neutrophil count, ESR erythrocyte segmentation rate, $h s C R P$ highly sensitive C-reactive protein, $T I B C$ total iron binding capacity, WBC white blood cell * $P$ value less than 0.05 was set to be statistically significant 
Table 3 Comparison of clinical features, endoscopic findings and tissues eosinophilia between the eosinophilic gastroenteritis (EoGE) ulcer and the non-EoGE ulcer group

\begin{tabular}{|c|c|c|c|}
\hline Variable & $\begin{array}{l}\text { Non-EoGE } \\
(N=236)\end{array}$ & $\begin{array}{l}\text { EoGE } \\
(N=19)\end{array}$ & $P$ value* \\
\hline \multicolumn{4}{|l|}{ Clinical features } \\
\hline Male gender (\%) & $142(60.2)$ & $15(78.9)$ & 0.105 \\
\hline Age, years & 10.2 (1-18 days) & $13.6(5.4-17.4)$ & 0.022 \\
\hline Complications & $18(7.6)$ & $3(15.8)$ & 0.197 \\
\hline Bleeding & $13(5.5)$ & $2(10.5)$ & 0.309 \\
\hline Obstruction & $3(1.3)$ & $1(5.3)$ & 0.268 \\
\hline Perforation & $2(0.8)$ & 0 & 1.000 \\
\hline Ulcer recurrence & $11(4.7)$ & $4(21.1)$ & 0.018 \\
\hline \multicolumn{4}{|l|}{ Allergic history } \\
\hline Atopic dermatitis & $5(2.1)$ & $5(26.3)$ & $<0.001$ \\
\hline Allergic rhinitis & $10(7.2)$ & $2(14.3)$ & 0.305 \\
\hline Asthma & $3(2.2)$ & 0 & 1.000 \\
\hline \multicolumn{4}{|l|}{ Endoscopic findings $\mathrm{n},(\%)$} \\
\hline Gastric ulcer only & $67(28.4)$ & $2(10.5)$ & 0.092 \\
\hline Duodenal ulcer only & $144(61.0)$ & 15 (78.9) & 0.121 \\
\hline Gastric and Duodenal ulcer & $25(10.5)$ & $2(10.5)$ & 1.000 \\
\hline Multiple ulcers & $69(29.2)$ & $4(21.1)$ & 0.448 \\
\hline Stomach nodularity & $36(15.3)$ & $5(26.3)$ & 0.202 \\
\hline Duodenal nodularity & $10(4.2)$ & 0 & 1.000 \\
\hline \multicolumn{4}{|c|}{ Tissue eosinophils (count/HPF) n, (range) } \\
\hline Upper esophagus & $0(0-4)$ & $0(0-103)$ & $<0.001$ \\
\hline Lower esophagus & $0(0-24)$ & $0(0-100)$ & $<0.001$ \\
\hline Stomach, antrum & $0(0-20)$ & $5(0-168)$ & $<0.001$ \\
\hline Stomach, body & $0(0-20)$ & $1(0-55)$ & $<0.001$ \\
\hline Duodenal bulb & $0(0-18)$ & $35(0-84)$ & $<0.001$ \\
\hline Duodenal 2nd portion & $0(0-42)$ & $25(0-100)$ & $<0.001$ \\
\hline
\end{tabular}

Data are expressed as Data are expressed as number (\%) for categorical variables or median (range) for continuous variables EoGE eosinophilic gastroenteritis, HPF high power field

* $P$ value less than 0.05 was set to be statistically significant

in developed countries [12, 20, 21], accounting for 2.8$6.0 \%$ of peptic ulcers and half of NSAID-associated ulcers $[20,21]$. Previous studies on the etiology of peptic ulcers have reported that idiopathic duodenal ulcers not associated with $H$. pylori or NSAIDs (HNGN-PU) were rare in the past.

However, in the recent years, the proportion of HNGN-PU among causes of peptic ulcers has been increasing gradually, due to decrease in the prevalence of H. pylori infection, because of effective prevention by environment improvement and antibiotic treatments, and increase in the proper use of NSAIDs [9-11, 22, 23]. Recent studies have showed that the prevalence of idiopathic peptic ulcers (e.g. HNGN-PU) was higher than that which was reported by previous studies $[6,16]$. Moreover, high prevalence of HNGN-PU in adults was recently reported in the USA and Australia [6]. In addition, there have been several case reports that peptic ulcers did not improve or recurred after $H$. pylori eradication. Furthermore, according to Laine et al., about $20 \%$ of duodenal ulcers recurred 6 months after successful eradication of H. pylori, in a meta-analysis of seven well-designed trials [13]. Charpignon et al. demonstrated that there were significant differences in the age of onset and the comorbidity of idiopathic peptic ulcer diseases (e.g. HNGN-PU), compared with both H. pylori and NSAIDs/aspirin-associated peptic ulcers [14]. However, the prevalence and clinical features of HNGN-PU in children has not been evaluated yet.

In the present study conducted for 14 years from July 2003 to April 2017, we recruited children with peptic ulcers and categorized them into 5 groups to investigate 
Table 4 Comparison of laboratory findings between the eosinophilic gastroenteritis (EoGE) ulcer and the non-EoGE ulcer group

\begin{tabular}{llll}
\hline Variable & $\begin{array}{l}\text { Non-EoGE } \\
(N=236)\end{array}$ & $\begin{array}{l}\text { EoGE } \\
(N=19)\end{array}$ & $P$ value \\
\hline WBC $(\times 103 / \mu l)$ & $7.47(3.2-29.7)$ & $6.4(4.2-10.3)$ & 0.130 \\
ANC $(\mu l)$ & $3710(521-22,933)$ & $3157(1819-6874)$ & 0.106 \\
Eosinophil $(\%)$ & $2.2(0-13.4)$ & $4.5(1.3-22.5)$ & 0.001 \\
Hematocrit $(\%)$ & $38.9(18.8-58.3)$ & $40(22.3-45.9)$ & 0.734 \\
Hemoglobin $(\mathrm{g} / \mathrm{dL})$ & $13.2(6.2-20.3)$ & $13.5(7.5-15.3)$ & 0.707 \\
Platelet $(\times 103 / \mu \mathrm{l})$ & $283(10-579)$ & $296(135-577)$ & 0.532 \\
Protein $(\mathrm{g} / \mathrm{dL})$ & $7.0(4.2-9.0)$ & $6.9(6.3-7.7)$ & 0.670 \\
Albumin $(\mathrm{g} / \mathrm{dL})$ & $4.4(2.4-5.4)$ & $4.4(3.8-5.5)$ & 0.683 \\
Iron $(\mu \mathrm{g} / \mathrm{dL})$ & $71(9.0-208)$ & $64.5(12.0-199)$ & 0.903 \\
Ferritin $(\mathrm{ng} / \mathrm{ml})$ & $37(1.9-217)$ & $44.0(4-164)$ & 0.848 \\
TIBC $(\mu \mathrm{g} / \mathrm{dL})$ & $365.5(188-580)$ & $265(251-463)$ & 0.997 \\
ESR $(\mathrm{mm} / \mathrm{hr})$ & $6(2-79)$ & $4(2-21)$ & 0.120 \\
hsCRP $(\mathrm{mg} / \mathrm{dL})$ & $0.14(0-24.6)$ & $0.02(0-5.3)$ & 0.059 \\
\hline Data & & &
\end{tabular}

Data are expressed as median (range)

ANC absolute neutrophil count, EOGE eosinophilic gastroenteritis, ESR erythrocyte segmentation rate, $h S C R P$ highly sensitive C-reactive protein, $T I B C$ total iron binding capacity, WBC white blood cell

* $P$ value less than 0.05 was set to be statistically significant

the differences in clinical features and the laboratory, endoscopic, and histopathologic findings of peptic ulcers in children, according to the etiology. Our study revealed that the proportion of $H$. pylori infection-associated ulcers and NSAIDs/aspirin-associated peptic ulcers were 20 and $7.1 \%$, respectively, in pediatric patients. The prevalence of $H$. pylori infection in Korean children declined to less than $10 \%$ in 2000 , implying that $H$. pylori is no longer the main cause of peptic ulcers. The notable point of our study results is that the proportion of HNGN-PU including idiopathic peptic ulcers, systemic diseases (Crohn's disease, HSP), and EoGE was relatively high, with 186 of 255 peptic ulcer cases $(72.9 \%)$ in children.

To date, most causes of HNGN-PU in children are unknown. EoGE is an etiology of HNGN-PU in adult patients and there have been studies stating that EoGE may be a cause of refractory peptic ulcer and several case reports of EoGE presenting with refractory peptic ulcer or perforated duodenal ulcer in both adults and children [24-26]. However, there were no studies on EoGE as a possible cause of HNGN-PU in children yet. In the present study, HNGN-PU was found to be relatively prevalent in children with peptic ulcer throughout the study period, and then EoGE emerged as a cause of HNGN-PU since we introduced a new endoscopic biopsy protocol to count tissue eosinophils in all specimens in 2011. In our study, 19 of 255 (7.5\%) patients with peptic ulcers were recently diagnosed with EoGE on the basis of clinical features and histopathologic findings of significant tissue eosinophil infiltrations, without any other organic diseases associated with gastrointestinal eosinophilia. No cases were diagnosed as EoGE ulcers before the year of 2011. Thus, the overall proportion of EoGE ulcers accounted for 10.2\% of 186 HNGN-PU in pediatric patients, which was $0 \%$ before 2011. All of these 19 EoGE cases were detected using the protocol of full tissue eosinophil evaluation by pathologists, without additional hospital costs.

In this study, increased blood eosinophil counts suggested EoGE, as if an increase in platelet, ESR, and hsCRP counts implied systemic diseases. This is consistent with previous reports that $50 \%$ of patients with EoGE disease had peripheral eosinophilia [17]; EoGE ulcer is a significant laboratory finding that cause suspicions. And EoGE among the 5 ulcer groups had more duodenal ulcers than gastric ulcers in our study. In the gastrotoxic drug group, however, multiple gastric ulcers were found to be more common. Notably, $52.9 \%$ of $H$ pylori infection and $26.3 \%$ of EoGE were expressed as nodular gastritis. Therefore, EoGE as well as $H$ pylori infection should be included in the differential diagnosis of nodular gastritis and duodenal ulcers in endoscopic findings.

This study has a few limitations. In a retrospective study, eosinophils cannot be counted through biopsy from the beginning of the study. And since there is no accurate drug history in some patients, it is likely that the gastrotoxic drug group has been misclassified as idiopathic group. In addition, the limitation of accurate diagnosis of $H$. pylori infection can also be a problematic issue that may increase the prevalence of HNGN-PU [27]. Since the diagnostic criteria for EoGE are still controversial, there is a possibility of overdiagnosis. A prospective study focusing on EoGE and consensus on diagnostic criteria is required in the future.

\section{Conclusions}

Our study revealed that the prevalence of EoGE ulcers in pediatric patients with HNGN-PU was $10.2 \%$, much higher than previously reported. In children with HNGN-PU, ulcer recurrence, peripheral eosinophilia, and history of atopic dermatitis might provide high levels of clinical suspicion for EoGE, requiring thorough histopathologic investigation of tissue eosinophils counts, on the basis of endoscopic biopsy.

\section{Supplementary information}

Supplementary information accompanies this paper at https://doi.org/10. 1186/s12876-020-01416-7.

Additional file 1: Supplement 1. Post-test, multiple comparison analysis of clinical features, endoscopic, histopathological, and laboratory findings in children with peptic ulcer according to the etiology of ulcer 


\section{Abbreviations}

H. pylori: Helicobacter pylori; HNGN-PU: H. pylori-negative and/or gastrotoxic drug-negative peptic ulcers (HNGN-PU); EoGE: Eosinophilic gastroenteritis; NSAIDs: Non-steroidal anti-inflammatory drugs; HSP: Henoch-Schönlein purpura; WBC: White blood cell count; ANC: Absolute neutrophil count; ESR: Erythrocyte sedimentation rate; hsCRP: Highly sensitive C-reactive protein

\section{Acknowledgements}

The authors would like to thank Dr. JB Lee from Seoul National University Bundang Hospital Medical Research Collaborating Center for her assistance in statistical analyses

\section{Authors' contributions}

JYJ: conduction of study, manuscript drafting. JMC: conduction of study, collection and interpretation of data. IHY: collection and interpretation of data. HRY: study design, interpretation of data, manuscript drafting. All authors have read and approved the final manuscripts.

\section{Funding}

This research received no specific grant from funding agency in the public commercial, or no-for- profit sectors.

\section{Availability of data and materials}

The datasets used and/or analyzed during the current study are available from the corresponding author on reasonable request.

\section{Ethics approval and consent to participate}

This retrospective study was approved by the Institutional Review Board (IRB) of Seoul National University Bundang Hospital (IRB No. B-1707/409-105).

\section{Consent for publication}

Not applicable.

\section{Competing interests}

The authors declare that they have no competing interests.

Received: 18 February 2020 Accepted: 7 August 2020

Published online: 20 August 2020

\section{References}

1. Malfertheiner P, Chan FKL, McColl KEL. Peptic ulcer disease. Lancet. 2009; 374:1449-61.

2. Marshall BJ, McGechie DB, Rogers PA, Glancy RJ. Pyloric campylobacter infection and gastroduodenal disease. Med J Aust. 1985;142:439-44.

3. Tytgat G, Langenberg W, Raws E, Rietra P. Campylobacter-like organism (CLO) in the human stomach. Gastroenterology. 1985:88:1620

4. NIH Consensus Development Panel on Helicobacter pylori in Peptic Ulcer Disease. Helicobacter pylori in peptic ulcer disease. JAMA. 1994;272:65-9.

5. Scarpignato C, Hunt RH. Nonsteroidal antiinflammatory drug-related injury to the gastrointestinal tract: clinical picture, pathogenesis, and prevention. Gastroenterol Clin N Am. 2010;39:433-64.

6. Arakawa T, Higuchi K, Fujiwara Y, Tominaga K, Watanabe T, Shiba M, Oshitani N, Matsumoto T. Has Helicobacter pylori eradication for peptic ulcer been overrated? Intern Med. 2004;43:179-83.

7. Pe'rez-Aisa MA, Del Pino D, Siles M, Lanas A. Clinical trends in ulcer diagnosis in a population with high prevalence of Helicobacter pylori infection. Aliment Pharmacol Ther. 2005:21:65-72.

8. Jiang JX, Liu Q, Mao XY, Zhang GX, Xu SF. Downward trend in the prevalence of Helicobacter pylori infections and corresponding frequent upper gastrointestinal diseases profile changes in southeastern China between 2003 and 2012. Springerplus. 2016;5:1601.

9. Sonnenberg A, Fritsch A. Changing mortality of peptic ulcer disease in Germany. Gastroenterology. 1983;84:1553-7.

10. Penston JG, Crombie IK, Waugh NR, Wornsley KG. Trends in morbidity and mortality from peptic ulcer disease: Tayside versus Scotland. Aliment Pharmacol Ther. 1993;7:429-42

11. McJunkin B, Sissoko M, Levien J, Upchurch J, Ahmed A. Dramatic decline in prevalence of Helicobacter pylori and peptic ulcer disease in an endoscopyreferral population. Am J Med. 2001;124:260-4.
12. Boulos PB, Botha A, Hobsley M, Holton J, Oshowo AO, Tovey FI. Possible absence of Helicobacter pylori in the early stages of duodenal ulceration. Q Med. 2002;95:749-52.

13. Laine L, Hopkins RJ, Girardi LS. Has the impact of Helicobacter pylori therapy on ulcer recurrence in the United States been overstated? A meta-anaylysis of rigorously designed trials. Am J Gastroentereol. 1998;93:1409-15.

14. Charpignon C, Lesgourgues B, Pariente A, Nahon S, Pelaquier A, GatineauSailliant G, Roucayrol AM, Courillon-Mallet A. Peptic ulcer disease: one in five is related to neither Helicobacter pylori nor aspirin/NSAID intake. Aliment Pharmacol Ther. 2013;38:946-54.

15. Nahon $S$, Hagège $H$, Latrive JP, Rosa I, Nalet B, Bour B, Faroux R, Gower $P$, Arpurt JP, Denis J, et al. Epidemiological and prognostic factors involved in upper gastrointestinal bleeding: results of a French prospective multicenter study. Endoscopy. 2012;44:998-1008.

16. Higuchi K, Arakawa T, Fujiwara Y, et al. Is Helicobacter pylori-negative duodenal ulcer masked by the high prevalence of $\mathrm{H}$. pylori infection in the general population? Am J Gastroenterol. 1999;94:3083-4.

17. Talley NJ, Shorter RG, Phillips SF, Zinsmeister AR. Eosinophilic gastroenteritis: a clinicopathological study of patients with disease of the mucosa, muscle layer, and subserosal tissues. Gut. 1990;31:54-8.

18. Yun MY, Cho YU, Park IS, Choi SK, Kim SJ, Shin SH, Kim KR. Eosinophilic gastroenteritis presenting as small bowel obstruction: a case report and review of the literature. World J Gastroenterol. 2007;13:1758-60

19. Caldwell JH, Tennenbaum Jl, Bronstein HA. Serum lgE in eosinophilic gastroenteritis. Response to intestinal challenge in two cases. N Engl J Med. 1975;292:1388-90

20. Borody TJ, George LL, Brandl S, Andrews P, Ostapowicz N, Hyland L, Devine M. Helicobacter pylori-negative duodenal ulcer. Am J Gastroenterol. 1991;86: 1154-7.

21. McColl KE, el-Nujumi AM, Chittajallu RS, Dahill SW, Dorrian CA, el-Omar E, Penman I, Fitzsimons EJ, Drain J, Graham H, et al. A study of the pathogenesis of Helicobacter pylori negative chronic duodenal ulceration. Gut 1993:34:762-8.

22. Xia B, Xia HH, Ma CW, Wong KW, Fung FM, Hui CK, Chan CK, Chan AO, La $\mathrm{KC}$, Yuen MF, et al. Trends in the prevalence of peptic ulcer disease and Helicobacter pylori infection in family physician-referred uninvestigated dyspeptic patients in Hong Kong. Aliment Pharmacol Ther. 2005:22:243-9.

23. Kearney DJ, Liu CF, Crump C, Brousal A. The effect of a Helicobacter pylori treatment strategy on health care expenditures in patients with peptic ulcer disease and dyspepsia. Am J Gastroenterol. 2003;98:1952-62.

24. Bischoff SC. Food allergy and eosinophilic gastroenteritis and colitis. Curr Opin Allergy Clin Immunol. 2010;10:238-45.

25. Kristopaitis T, Neghme C, Yong SL, Chejfec G, Aranha G, Keshavarzian A. Giant antral ulcer: a rare presentation of eosinophilic gastroenteritis-case report and review of the literature. Am J Gastroenterol. 1997;92:1205-8.

26. Scolapio JS, DeVault K, Wolfe JT. Eosinophilic gastroenteritis presenting as a giant gastric ulcer. Am J Gastroenterol. 1996;91:804-5.

27. lijima K, Kanno T, Koike T, Shimosegawa T. Helicobacter pylori-negative, nonsteroidal anti-inflammatory drug: negative idiopathic ulcers in Asia. World J Gastroenterol. 2014:20:706-13.

\section{Publisher's Note}

Springer Nature remains neutral with regard to jurisdictional claims in published maps and institutional affiliations.

Ready to submit your research? Choose BMC and benefit from:

- fast, convenient online submission

- thorough peer review by experienced researchers in your field

- rapid publication on acceptance

- support for research data, including large and complex data types

- gold Open Access which fosters wider collaboration and increased citations

- maximum visibility for your research: over $100 \mathrm{M}$ website views per year

At BMC, research is always in progress.

Learn more biomedcentral.com/submission 